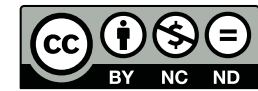

Estudos Teológicos foi licenciado com uma Licença Creative Commons Atribuição - NãoComercial - SemDerivados 3.0 Não Adaptada

http://dx.doi.org/10.22351/et.v.57i2.2713

\title{
O Rosário em Campinas: Religiosidades negras, FlutuaÇão ARQUITETÔNICA E CULTURA MATERIAL NA EXTENSÃO UNIVERSITÁRIA ${ }^{1}$
}

\author{
The Rosary in Campinas: black religiosities, architectural floating \\ and material culture in university extension
}

\section{Fábio Augusto Morales ${ }^{2}$ Camila Médici Neves ${ }^{3}$}

\begin{abstract}
Resumo: Como parte do projeto de extensão "Lugares da religião em Campinas: espaço, patrimônio e cultura material", este artigo discute as dimensões espaciais e históricas do culto ao rosário em Campinas/SP, tomando como estudo de caso a história "flutuante" da Igreja da Nossa Senhora do Rosário no centro da cidade. Após uma breve discussão teórica, o artigo realiza um movimento partindo das recentes notícias arqueológicas relacionadas à igreja até os inícios do culto ao rosário na Europa, e conclui com uma discussão acerca das possibilidades desse exercício para a promoção da tolerância religiosa e da valorização do patrimônio cultural em atividades de extensão com professores da rede pública local.

Palavras-chave: Igreja do Rosário em Campinas. Patrimônio cultural. Virada espacial. Ciências da Religião. Extensão universitária.
\end{abstract}

Abstract: As part of the extension project 'Places of Religion in Campinas: space, heritage and material culture', this paper discusses the spatial and historical dimensions of the Rosary cult in Campinas/SP, taking as case-study the 'floating' history of the Our Lady of the Rosary Church at city center. After a brief theoretical discussion, the paper proposes a movement from the contemporary archaeological news about the Church to the beginnings of the Rosary cult in Europe, and concludes with a discussion about the possibilities of this exercise for the promotion of religious tolerance and valorization of cultural heritage in extension activities with teachers of local public schools.

Keywords: Rosary Church of Campinas. Cultural heritage. Spatial turn. Religious studies. University extension.

1 O artigo foi recebido em 25 de março de 2016 e aprovado em 22 de maio de 2017 com base nas avaliações dos pareceristas ad hoc.

2 Doutor em História Social pela Universidade de São Paulo; docente extensionista do Programa de Mestrado em Ciências da Religião da Pontifícia Universidade Católica de Campinas (PUC-Campinas), responsável pelo projeto "Lugares da Religião em Campinas: espaço, patrimônio e cultura material" (2015-2017); docente da Faculdade de História da Pontifícia Universidade Católica de Campinas (PUC-Campinas). contato: fabio.augusto@puc-campinas.edu.br

3 Graduanda em História pela Pontifícia Universidade Católica de Campinas (PUC-Campinas), bolsista de extensão do projeto "Lugares da Religião em Campinas: espaço, patrimônio e cultura material" no ano de 2015 . 


\section{Introdução}

A história do culto do Rosário em Campinas/SP é um dos mais interessantes - e pouco estudados em sua multiplicidade de dimensões - casos para se pensar as articulações entre religião, arquitetura e cultura material. Da luta contra heresias medievais à identidade de igrejas transplantadas no século XX, o culto ao Rosário em Campinas carrega diversas camadas históricas e espaciais cujo conhecimento é estratégico para a elaboração de práticas educacionais e políticas voltadas para o patrimônio cultural local. O presente artigo discutirá a historicidade do culto ao Rosário em Campinas em virtude de sua inclusão no conjunto de oficinas do projeto de extensão universitária intitulado "Lugares da Religião em Campinas", realizado pela PUC-Campinas em parceria com três escolas estaduais da região. Para tanto, o artigo está dividido em três partes: uma aproximação teórica aos problemas vinculados a uma abordagem arqueológica e espacial do fenômeno religioso; uma exploração das diversas camadas relacionadas à historicidade do culto ao Rosário em Campinas, da Idade Média ao século XXI; e uma explicitação do modo pelo qual tais camadas foram engajadas nas oficinas do projeto de extensão universitária em questão.

\section{Religião, cultura material e arquitetura}

Dadas as múltiplas definições apontadas nos últimos séculos para o fenômeno religioso, é consenso de que religião é, ao menos, um objeto interdisciplinar. ${ }^{4}$ Longe de serem monopolizados pelas ciências da religião, aspectos do que socialmente se considerou como "religião" foram objeto das mais diversas ciências humanas parcelares, muitas vezes fragmentando uma realidade em si totalizante. Assim, arquitetos analisaram os desenvolvimentos técnicos e conceituais de templos e edifícios sagrados ao longo da história ${ }^{5}$; geógrafos mapearam os territórios sagrados, reais e/ ou imaginados ${ }^{6}$; sociólogos e antropólogos analisaram mitos e rituais em busca das estruturas (ou singularidades) sociais ${ }^{7}$; historiadores analisaram as transformações de doutrinas e instituições ao longo do tempo ${ }^{8}$; arqueólogos analisaram objetos e contextos interpretáveis (não sem polêmicas) como "rituais" e sua articulação com a cultura

4 SEGAL, Robert (ed.). The Blackwell Companion to the Study of Religion. Oxford: Blackwell, 2006; PASSOS, João Décio; USARSKI, Frank (orgs.). Compêndio de Ciência da Religião. São Paulo: Paulinas; Paulus, 2013.

5 WIEBE, Paul. The Architecture of Religion: A Theoretical Essay. San Antonio: Trinity University Press, 1984; BERGMANN, Sigurd (ed.). Architecture, Aesth/Ethics and Religion. Frankfurt am Main; London: IKO-Verlag für Interkulturelle Kommunikation, 2005.

6 PARK, Chris. Religion and Geography. In: HINNELLS, J. (ed.). The Routledge Companion to the Study of Religion. London; New York: Routledge, 2005. p. 439-455.

7 BELL, Catherine. Ritual. Perspectives and Dimensions. Oxford: Oxford University Press, 1997.

8 SILVA, Eliane Moura da. Entre religião, cultura e história: a escola italiana das religiões. Revista de Ciências Humanas, Viçosa, v. 11, n. 2, p. 225-234, 2011. 
material das sociedades ${ }^{9}$; filósofos e teólogos buscaram as essências ou fundamentos dos fenômenos religiosos ${ }^{10}$ etc. Certamente, não é objeto deste artigo propor uma interpretação total e objetiva do fenômeno religioso, empreendimento impossível e mesmo indesejável, tendo em vista os benefícios da multivocalidade no atual contexto da produção em ciências humanas ${ }^{11}$; pelo contrário, buscaremos neste texto sugerir uma abordagem que atravesse as diferentes ciências parcelares a partir de um conjunto coerente de questões, a saber, as questões espaciais.

Tal abordagem se vincula ao que tem sido chamado de spatial turn, movimento - ou movimentação - nas ciências humanas que tem suas raízes nas décadas de 1950 e 1960, mas somente na década de 1990 exerceu um impacto interdisciplinar da estatura das "viradas" anteriores. ${ }^{12}$ Fazendo jus ao seu estatuto acadêmico, a virada espacial apresenta uma enorme diversidade de abordagens, teorias, métodos e problemas, muitos deles fecundos para o estudo das religiões. ${ }^{13}$ Para a presente análise, dois conjuntos conceituais relacionados às "questões espaciais" serão engajados: em primeiro lugar, a discussão da heterotopologia proposta por Michel Foucault em um (terrivelmente curto) artigo publicado em 1984, a partir de conferência pronunciada em $1967^{14}$, que propõe a análise dos espaços que tem a potencialidade de se remeterem a outros espaços, em particular por meio da narrativa; em segundo lugar, retomaremos o método regressivo-progressivo de Henri Lefebvre, exposto de modo não sistemático em dois artigos voltados para a questão da sociologia rural. ${ }^{15} \mathrm{~A}$ partir da heterotopologia, analisaremos o modo como um determinado espaço se articula a outros espaços por meio de relações sociais de produção específicas; do método regressivo-progressivo, reteremos o percurso por meio das diversas camadas históricas dos espaços em questão, do presente ao passado e novamente ao presente, demonstrando assim sua densidade e diversidade.

Antes de partirmos para o estudo de caso, vale a pena mencionar, ainda que brevemente, uma questão crucial: a relação entre arquitetura, história e flutuação. A arquitetura foi concebida, alternadamente, como discurso e prática da construção de edifícios e seus estilos, de espaços a partir da articulação de espaços edificados e espa-

9 INSOLL, Timothy. Archaeology, Ritual, Religion. London; New York: Routledge, 2004. WESLER, Kit. An Archaeology of Religion. Lanham: University Press of America, 2012. DROOGAN, Julian. Religion, Material Culture and Archaeology. London: Bloomsbury, 2013.

${ }^{10}$ QUINN, Philip; TALIAFERRO, Charles (eds.). Companion to Philosophy of Religion. Oxford: Blackwell, 1999.

${ }^{11}$ HABU, Junko; FAWCETT, Clare; MATSUNAGA, John. Evaluating Multiple Narratives: Beyond Nationalist, Colonialist, Imperialist Archaeologies. Springer: New York, 2008.

12 WARF, Barney; ARIAS, Santa (eds.). The Spatial Turn: Interdisciplinary Perspectives. Routledge: New York, 2009.

${ }^{13}$ KNOTT, Kim. Spatial theory and method for the study of religion. Temenos, v. 41, n. 2, p. 153-184, 2005.

${ }_{14}^{14}$ FOUCAULT, Michel. De espaços outros. Estudos Avançados, v. 27, n. 79, p. 113-122, 2013.

${ }^{15}$ LEFEBVRE, Henri. Problèmes de Sociologie Rurale: La Communauté Paysanne et ses Problémes Historico-Sociologiques. Cahiers Internationaux de Sociologie, v. 6, p. 78-100, 1949. LEFEBVRE, Henri. Perspectives de la Sociologie Rurale. Cahiers Internationaux de Sociologie, v. 14, p. 122-140, 1953. FREHSE, Fraya. Potencialidades do método regressivo-progressivo. Pensar a cidade, pensar a história. Tempo Social, v. 13, n. 2, p. 169-184, 2001. 
ços não edificados, ou de signos a partir da articulação de edifícios e espaços. ${ }^{16}$ Tal visão reificada da arquitetura está na base da historiografia da arquitetura como história dos arquitetos e suas criações. ${ }^{17}$ Para além de uma visão centrada na obra do arquiteto - cuja distinção do engenheiro, mestre de obras e artista não foi de modo algum absoluta na história construtiva das sociedades ${ }^{18}$-, a arquitetura, sob influência do spatial $t u r n^{19}$, tem sido repensada como momento da reprodução da sociedade por meio da produção do espaço, assim relacionando-se com as esferas político-institucionais e econômicas (a economia política da cidade de Harvey) assim como a multiplicidades de significados e modos de produção do espaço (na trialética de Lefebvre). A arquitetura, portanto, estaria na relação estabelecida entre diferentes agentes envolvidos na produção social do espaço; a história da arquitetura deve ser necessariamente uma história social.

Por outro lado, o edifício não se reduz à arquitetura. As diferentes etapas de seu programa - procura, manufatura, uso, descarte ${ }^{20}$ - fazem com que um edifício tenha múltiplas dimensões: obra de arte, dedicação religiosa, discurso político, abrigo contra intempéries, investimento econômico, metáfora etc. Tome-se, por exemplo, os estádios para a Copa do Mundo, que não podem ser tomados apenas como soluções construtivas para necessidades esportivas, mas congregam diferentes aspectos da realidade social. Edifícios são fatos sociais totais, na medida em que a sociedade produz neles e se reproduz por eles. A análise histórica de um edifício, portanto, não pode se limitar à sua arquitetura (seja no sentido estrito, projetocêntrico, seja no seu sentido mais amplo, de objeto da produção social do espaço), mas deve levar em consideração as diferentes dimensões ou esferas da vida social engajadas nos diferentes momentos de sua história enquanto elemento da cultura material de uma sociedade. ${ }^{21}$ A história espacial deve, ademais, considerar as constantes flutuações pelas quais passam os edifícios.

Ora, relacionar arquitetura e flutuação pode parecer um disparate: afinal, edifícios têm estruturas que o fixam a um determinado espaço, definidas ainda no projeto. A ênfase na fixação, associada materialmente às estruturas e idealmente ao projeto, no entanto, deixa de lado toda uma realidade de intensa flutuação material e semântica inerente às tentativas de fixação. Não cabe aqui realizar uma ontologia do espaço

${ }^{16}$ GONÇALVES, Denise. Uma história da historiografia de arquitetura - texto e imagem na definição de uma disciplina. ArtCultura, Uberlândia, v. 12, n. 20, p. 95-115, jan./jun. 2010. STANEK, Lukasz. Architecture as Space, Again? Notes on the 'Spatial Turn'. Spéciale 'Z, Paris, n. 4, p. 48-53, 2012.

17 ARNOLD, Dana; ERGUT, Elvan Altan; ÖZKAYA, Belgin Turan (eds.). Rethinking Architectural Historiography. London; New York, 2006.

18 PARETO JR., Lindener. Pândegos, rábulas, gamelas: os construtores não diplomados entre a engenharia e a arquitetura (1890-1960). 2016. 350ff. Tese (Doutorado) - Faculdade de Arquitetura e Urbanismo, Universidade de São Paulo, São Paulo. 2016..

19 STANEK, 2012, p. 51-52.

${ }^{20}$ BRUNEAU, Philipe. Quatre propos sur l'archéologie nouvelle. Bulletin de correspondance hellénique, v. 100, n. 1, p. 103-135, 1976. SCHIFFER, Michael. Behavioral Archaeology. New York: Academic Press, 1976. OTTO, Christian. Program and programs. In: ARNOLD, D.; ERGUT, E.; ÖZKAYA, B. (eds.). Rethinking Architectural Historiography. London; New York, 2006. p. 50-59.

${ }^{21}$ MENESES, Ulpiano Toledo Bezerra de. A cultura material no estudo das sociedades antigas. Revista de História, n. 115, p. 103-117, 1983. 
- tema que tem sido retomado com especial intensidade a partir da abordagem heideggeriana ${ }^{22}$-, mas de constatar o modo como sentidos associados aos edifícios e os edifícios mesmos flutuaram no espaço social e na cultura material das sociedades. A flutuação de sentidos - do projeto ao uso e aos reusos e aos descartes - é uma área exaustivamente estudada para os mais diversos períodos históricos ${ }^{23}$, por exemplo, a cristianização de templos pagãos ou a patrimonialização de edifícios considerados "históricos". Já uma história social da flutuação material de edifícios é campo ainda em formação. ${ }^{24}$ Estudos pontuais foram realizados, mas raramente postos em comparação ou analisados pela ótica da flutuação. Neste texto, trataremos de uma das mais significativas histórias de flutuação material: a transposição da Igreja do Rosário em Campinas. Comecemos, portanto, do princípio.

\section{Flutuação e alteridade}

A partir de fevereiro de 2015, a avenida Francisco Glicério, no centro de Campinas, foi objeto de uma nova obra de "revitalização": redes de esgoto e água foram trocadas, a rede de energia elétrica foi enterrada, calçadas foram ampliadas e a via foi recapeada. ${ }^{25}$ Durante as escavações no trecho da praça Visconde de Indaiatuba, em junho do mesmo ano, foram encontrados tijolos das fundações da antiga Igreja Nossa Senhora do Rosário. $\mathrm{O}$ achado, noticiado na imprensa local $^{26}$, é a ponta do iceberg de uma longuíssima história de flutuações materiais e conceituais relacionadas ao culto do "rosário", cujo fio seguiremos aqui retrospectivamente.

A Igreja da Nossa Senhora do Rosário se situava no local do achado até 1956, quando foi demolida (figuras 1 e 2). Então a Prefeitura Municipal da cidade dava prosseguimento à execução do Plano de Melhoramentos Urbanos desenhado pelo engenheiro e ex-prefeito de São Paulo Francisco Prestes Maia entre os anos 1934 e 1938, e previa a ampliação da urbanização para a região norte (tendo a construção da "étoille" da Torre do Castelo como eixo, com forte influência da reforma haussmaniana de Paris) e a ampliação das avenidas da região central da cidade, entre as quais a avenida

22 SARAMAGO, Ligia Teresa. A topologia do ser: lugar, espaço e linguagem no pensamento de Martin Heidegger. Rio de Janeiro: PUC-Rio; Loyola, 2008.

23 WHYTE, William. How Do Buildings Mean? Some Issues of Interpretation in the History of Architecture. History and Theory, v. 45, n. 2, p. 153-177, 2006.

24 DINSMOOR Jr., William. Anchoring Two Floating Temples. Hesperia, v. 51, p. 410-452, 1982.

25 Informações no portal de notícias da PREFEITURA MUNICIPAL DE CAMPINAS. Obras de revitalização da Francisco Glicério seguem em ritmo acelerado. Notícia publicada no dia 06/03/2015, às 19:15h, no Portal da Prefeitura Municial de Campinas. Disponível em: <http://www.campinas.sp.gov.br/noticias-integra.php?id=26226>. Acesso em: dez. 2015. Para a crítica do uso do termo "revitalização" para intervenções públicas no espaço urbano, cf. SMITH, Neil. Gentrificação, a fronteira e a reestruturação do espaço urbano. GEOUSP: espaço e tempo, n. 21, p. 15-31, 2007.

${ }^{26}$ STEGANHA, Roberta. Escavações revelam parte da antiga Igreja do Rosário em Campinas, SP. Portal G1 Campinas e Região, publicada em 30/06/2015, às 07:01h. Disponível em: <http://g1.globo.com/sp/ campinas-regiao/noticia/2015/06/escavacoes-revelam-parte-da-antiga-igreja-do-rosario-em-campinas-sp. html>. Acesso em: 25 mar. 2016. 
Francisco Glicério. ${ }^{27} \mathrm{O}$ plano se baseava fortemente no urbanismo norte-americano ${ }^{28}$ e no exemplo prático da execução do Plano de Avenidas em São Paulo durante a gestão de Prestes Maia como prefeito entre 1926-1930. Em Campinas, a construção de uma cidade moderna e industrial - superando assim o período dominado pela cafeicultura - passava pelo apagamento das marcas da cidade colonial, dominada pela tradição portuguesa e pelo catolicismo: a demolição da igreja para a conversão da praça Visconde de Indaiatuba em um centro cívico é sintomática desse processo, assim como as alterações na fachada que diminuíram as marcas barrocas e reforçaram as referências neorromânicas. A demolição ocorre finalmente em $1956^{29}$, mesmo ano em se inicia a construção da nova igreja (completada somente em 1989) a cerca de 2 $\mathrm{Km}$ de distância, justamente em uma das avenidas que irradiavam do centro da étoile do Jardim Chapadão. Assim, o espaço urbano campineiro remetia-se às paisagens de Paris, Chicago e São Paulo, em uma peculiar heterotopia da modernidade urbana.

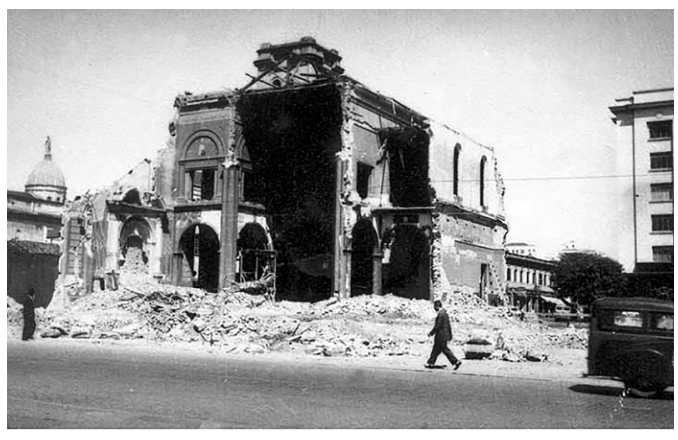

Figura 1. Igreja do Rosário parcialmente demolida, em 1956. Fotografia de Aristides Pedro da Silva (GONÇALVES; MARCONDES, 2005, p. 255).

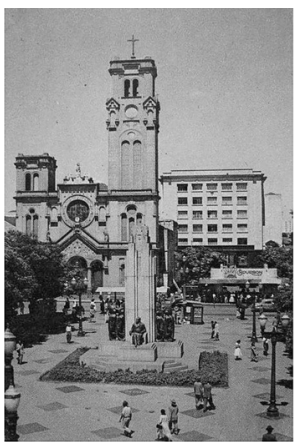

Figura 2. Postal da cidade de Campinas, colorizado, com imagem da Igreja do Rosário na década de 1950, pouco antes da demolição (Acervo do Centro de Ciências, Letras e Artes de Campinas; apud ROSADA, 2010, p. 112).

${ }^{27}$ BADARÓ, Ricardo. Plano de Melhoramentos Urbanos de Campinas (1934-1962). 1986. Dissertação (Mestrado) - Faculdade de Arquitetura e Urbanismo, Universidade de São Paulo, São Paulo, 1986.

Campinas, o despontar da modernidade. Campinas: Centro de Memória da Unicamp, 1996. CARPINTERO, Antônio Carlos Cabral. Momento De Ruptura: as transformações no centro de Campinas na década dos cinqüenta. Campinas: Centro de Memória da Unicamp, 1996. ZAKIA, Sílvia Amaral Palazzi. Construção, arquitetura e configuração urbana de Campinas nas décadas de 1930 e 1940: o papel de quatro engenheiros modernos. 2012. Tese (Doutorado) - Faculdade de Arquitetura e Urbanismo, Universidade de São Paulo, 2012. p. 14-85.

${ }_{28}$ ZAKIA, 2012, p. 47-49.

${ }^{29}$ CONDEPACC [Conselho de Defesa do Patrimônio Artístico e Cultural de Campinas]. Tombamento da Praça Visconde de Indaiatuba. Campinas, 1994. ROSADA, Mateus. Sob o signo da cruz: Igreja, Estado e secularização (Campinas e Limeira 1774-1939). 2010. Dissertação (Mestrado) - Escola de Engenharia de São Carlos, Universidade de São Paulo, 2010. p. 110-114. CASTRO, Marina. Igreja Nossa Senhora do Rosário: a não preservação de um patrimônio urbano em 1956. 2014. Monografia (Especialização em História e Patrimônio Cultural) - Pontifícia Universidade Católica de Campinas, Campinas, 2014. 
A praça Visconde de Indaiatuba, onde se localizava a igreja, passou a se chamar oficialmente assim somente em 1896: antes, chamava-se Largo do Rosário. O mesmo ocorrera antes, em 1889, com a antiga rua do Rosário, que passou a se chamar avenida Francisco Glicério. A alteração do nome da praça e da rua - da vinculação a um culto fortemente associado às religiosidades negras locais à comemoração de políticos locais - se compreende nos termos do enfraquecimento da Igreja do Rosário na paisagem religiosa das elites campineiras, especialmente após o termino da construção da Catedral Metropolitana, em 1883, após mais de 70 anos de obras. Com o estado precário da antiga Igreja Matriz da cidade - no local da atual Basílica do Carmo - e a inconclusão da Catedral Metropolitana, a Igreja do Rosário assumiu o posto de Igreja Matriz ao menos em duas ocasiões: da visita de D. Pedro II em 1846 a 1852 , e de 1870 a 1883 . A transformação da antiga igreja dos mulatos em Igreja Matriz levou a um duplo movimento: se, por um lado, o edifício seria reforçado e sua fachada ornamentada ${ }^{30}$ (figura 3), por outro, a população negra que frequentava o culto foi paulatinamente expulsa do local, transferindo suas atividades para a paróquia de São Benedito (um santo siciliano de ascendência etíope, segundo suas hagiografias), mais ao sul, também tradicional polo de expressão da religiosidade negra campineira. Desse modo, a flutuação do estatuto administrativo da cidade - de freguesia a vila, de vila a cidade - intimamente relacionado ao processo de afirmação dos proprietários de terra locais no âmbito do Estado Nacional em formação, implicava a colonização e o deslocamento de espaços e sociabilidades religiosas negras locais.

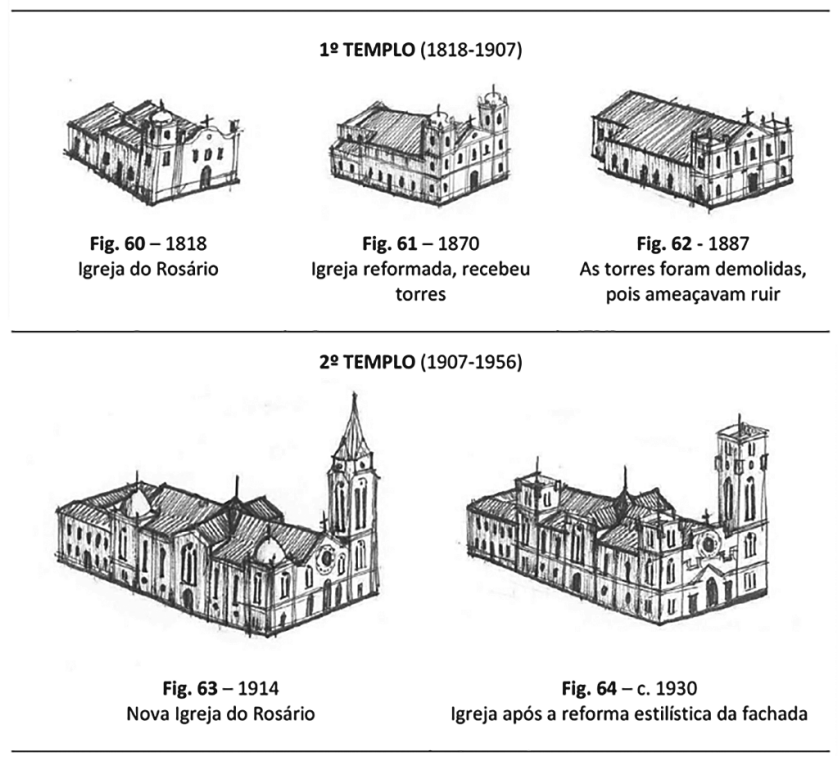

Figura 3. Fases construtivas da Igreja do Rosário de Campinas.

Desenho de Matheus Rosada (2010, p. 113-114)

${ }^{30}$ ROSADA, 2010, p. 110. 
A Igreja do Rosário foi construída com técnica de taipa de pilão em $1817 .{ }^{31}$ Pouco se sabe acerca dos agentes envolvidos em sua construção, mas é certo que seu culto se articulava à devoção das irmandades negras da cidade, diferente da Igreja da Nossa Senhora da Conceição, então Igreja Matriz (situada nas proximidades de onde hoje está o monumento fúnebre de Carlos Gomes), polo da religiosidade das elites locais e primeira capela da freguesia da Nossa Senhora da Conceição do Mato Grosso, fundada em 1774. A devoção ao rosário, sem dúvida, não era exclusiva da população negra: uma imagem da Nossa Senhora do Rosário, atualmente no Museu Arquidiocesano de Campinas, já estava presente na capela de 1774 (figura 4). A Igreja do Rosário de Campinas seguia, dessa maneira, uma já consolidada tradição de inclusão da população escrava e liberta no catolicismo por meio da associação ao culto da Nossa Senhora do Rosário, como demonstra a grande disseminação e enraizamento das irmandades na América portuguesa. ${ }^{32}$ A vinculação entre a população negra e o culto ao Rosário remonta às primeiras incursões portuguesas na África no século XV, em particular com a ação de missionários dominicanos no reino do Congo; tanto na África como em Portugal, multiplicam-se as irmandades formadas por africanos cativos e libertos. ${ }^{33}$

Muito se discutiu a respeito do significado da formação dessas comunidades do ponto de vista dos africanos ${ }^{34}$, defendendo-se desde explicações com base em processos de apropriação cultural (o rosário de Nossa Senhora como um duplo do colar do orixá Ifã) ou de integração social (o pertencimento a uma irmandade como estratégia de inclusão nas estruturas sociais dos dominadores); não obstante, vale a pena ainda ressaltar o papel do rosário do ponto de vista dos europeus, durante a expansão e a escravização em massa de populações africanas. O rosário de Nossa Senhora não era exclusivamente vinculado à África e à relação com os africanos: diversos indícios apontam que tal objeto sagrado, para além dos usos cotidianos de comunicação com o sagrado, era utilizado como espécie de objeto alteritário, possibilitando a comunicação com os "outros" da cristandade, especialmente em contextos de conflito. ${ }^{35}$ Por exemplo, vale lembrar a recomendação papal para a recitação do rosário em benefício dos cristãos na batalha de Lepanto, em 1571, contra o império turco, interpretada como um dos ingredientes da vitória cristã. A narrativa da origem do culto ao Rosário,

${ }^{31}$ CONDEPACC, 1994.

${ }^{32}$ KIDDY, Elizabeth. Congados, Calunga, Candombe: Our Lady of the Rosary in Minas Gerais, Brazil. Luso-Brazilian Review, v. 37, n. 1, p. 47-61, 2000. REGINALDO, Lucilene. Os Rosários dos Angolas: irmandades de africanos e crioulos na Bahia setecentista. São Paulo: Alameda, 2011.

33 TINHORÃO, José Ramos. Os Negros em Portugal. Uma presença silenciosa. Lisboa: Caminho, 1997. LAHON, Didier. Esclavage et Confréries Noires au Portugal durant l'Ancien Régime (1441-1830). 2001. Tese (Doutorado) - École des Hautes Études en Sciences Sociales, Paris, 2001.

${ }^{34}$ SIMÃO, Maristela. As irmandades de Nossa Senhora do Rosário e os africanos no Brasil do século XVIII. 2010. Dissertação (Mestrado em História da África) - Faculdade de Letras, Universidade de Lisboa, 2010. REGINALDO, 2011.

${ }^{35}$ SOUZA, Juliana Beatriz Almeida de. Viagens do Rosário entre a Velha Cristandade e o Além-Mar. Estudos Afro-Asiáticos, ano 23, n. 2, p. 1-17, 2001. 
por sua vez, é ainda mais clara. De acordo com tradições tardias ${ }^{36}$, durante sua preparação espiritual para o conflito contra os albigenses - que apresentavam versões alternativas do cristianismo, rapidamente classificados como hereges pela igreja -, São Domingos foi visitado na Igreja de Prouilhe, no sul da França, pela própria Maria, que lhe deu o saltério, cuja devoção garantiria a vitória sobre os "hereges". O longo colar de contas (cerca de 150), cujo uso como marcador de rezas provavelmente estivesse associado à leitura monástica dos 150 salmos e rituais paralelos entre os leigos ${ }^{37}$, ao longo da Idade Média foi cada vez mais associado ao contato dos cristãos com os infiéis, em particular após a divulgação, no final do século XV, dos escritos em alemão do dominicano britânico Alano da Rocha (figura 5), que associava a devoção ao rosário à garantia da vitória contra o pecado e as heresias. ${ }^{38}$

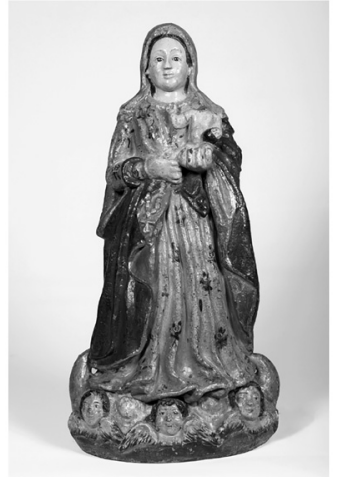

Figura 4. Imagem de Nossa Senhora do Rosário (1774), em barro policromado (Acervo do Museu Arquidiocesano de Campinas; apud BARRANTES, 2014, p. 66).

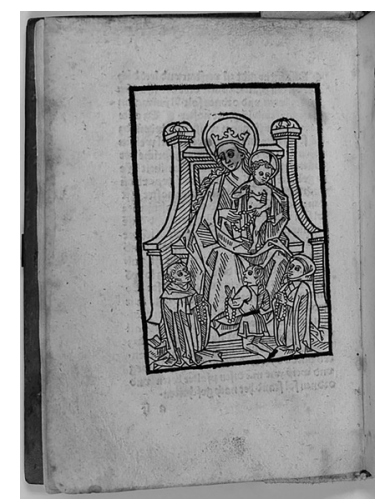

Figura 5. Página do Saltério e Rosário de Nossa Senhora, de Alano da Rocha, impresso em 1492 (Wikicommons ${ }^{39}$ ).

Façamos de volta o percurso: o rosário, incorporado no culto católico como objeto alteritário de contato com a heresia e matriz de ordens religiosas, é ressignificado como objeto de devoção de população convertida sob a escravidão; no contexto colonial, o culto ao rosário torna-se importante mecanismo de incorporação de segmentos da população escravizada na sociedade escravista, abrindo a possibilidade para o aparecimento de formas híbridas de religiosidade, nas quais a forte presença negra estaria no cerne de seu deslocamento e apagamento no processo de transforma-

\footnotetext{
${ }^{36}$ WINSTON-ALLEN, Anne. Stories of the Rose: The Making of the Rosary in the Middle Ages. Philadelphia: Pennsylvania University Press, 1997. MITCHELL, Nathan. The Mystery of the Rosary: Marian Devotion and the Reinvention of Catholicism. New York: New York University Press, 2009.

${ }^{37}$ BOSS, Sarah Jane. Telling the Beads: the practice and symbolism of the rosary. In: BOSS, Sarah Jane. (ed). Mary: the complete resource. London: Continuum, 2007. p. 385-394.

38 WINSTON-ALLEN, 1997, p. 66-67.

39 Disponível em: <https://fr.wikipedia.org/wiki/Fichier:Alanus_Psalter_a2v-1.JPG>. Acesso em: 25 mar. 2016.
} 
ção da cidade, de vila colonial à cidade cafeicultora, e então à metrópole industrial. A história do culto e da Igreja do Rosário em Campinas é, pois, extremamente rica para pensar não apenas a conformação da paisagem urbana em função das diferentes tradições recebidas e incorporadas pela sociedade local, como a permanência das problemáticas de inclusão/exclusão da população afrodescendente nos quadros da religiosidade campineira.

\section{O rosário na extensão universitária}

A discussão sobre a história do culto ao Rosário em Campinas foi incorporada em diversas oficinas do projeto de extensão "Lugares da Religião em Campinas: espaço, patrimônio e cultura material", que teve lugar em três escolas estaduais da região metropolitana de Campinas ao longo do ano letivo de 2015. As escolas participantes foram: EE Luis Gonzaga Horta Lisboa, no bairro Jardim Miriam; EE Tomás Alves, no distrito de Sousas; e EE Francisco Barreto Leme, no distrito de Joaquim Egídio. As oficinas eram realizadas junto aos professores dos ensinos fundamental e médio, no horário disponibilizado pela coordenação da escola: a saber, duas horas por mês durante a aula de trabalho pedagógico coletivo - ATPC. O objetivo central do projeto era o de combater a intolerância religiosa nas escolas por meio, essencialmente, de duas estratégias: aprofundar o conhecimento dos docentes a respeito das tradições religiosas mais próximas (as diversas formas de cristianismo), ao mesmo tempo em que eram realizadas comparações com tradições aparentemente mais distantes (como o islamismo e o budismo) ou próximas, mas segregadas (a umbanda e o candomblé), de modo a demonstrar os contatos entre formas de religiosidade à primeira vista opostas. Um segundo objetivo era o de valorizar o patrimônio cultural local do ponto de vista da diversidade religiosa, articulando-se, obviamente, ao combate à intolerância.

Dois tipos de oficinas foram realizados: as reuniões durante as ATPCs nas escolas (com quatro grupos de professores) e estudos do meio em diferentes sítios religiosos espalhados na cidade. As primeiras oficinas tiveram como objeto o catolicismo campineiro, em virtude de ser a religião mais representada tanto na população total como entre os docentes participantes. Nas oficinas realizadas nas escolas foram discutidas as tradições arquitetônicas presentes nas diferentes igrejas católicas de Campinas, assim como foi mencionada, de passagem, a história da transposição da Igreja do Rosário. Essa história seria retomada durante o primeiro estudo do meio, realizado no último sábado do mês de abril, seguindo um percurso que começava na Catedral Metropolitana, passava pelo Largo do Rosário e terminava na Basílica do Carmo. Durante o passeio, ficou evidente o conhecimento superficial dos participantes a respeito da história espacial daquelas igrejas, e mesmo o completo desconhecimento da existência de uma igreja no "Largo do Rosário" - cujo nome não oficial permaneceu de amplo uso apesar de chamar-se "praça Visconde de Indaiatuba" desde 1887 e não ter mais uma igreja homônima desde 1956. O papel do racismo e da cultura colonialista (tendo como matrizes a Europa ou os Estados Unidos) como elementos estruturantes da produção do espaço urbano foi ressaltado ao longo dos debates in loco, ao 
mesmo tempo em que a narrativa permitia que os participantes remetessem aquele espaço cotidiano a outros espaços (à étoile de Paris, a vias automotivas de Chicago, às avenidas de São Paulo, às missões no Congo, aos conventos em Lisboa, às aparições em Prouille etc.); procurou-se, com isso, intensificar a densidade da relação espacial crítica dos sujeitos com o Largo, vazio de igrejas e cultos, mas repleto de referências temporais e espaciais mediadas pelo conhecimento. Foi consenso, após deixarmos o local, a necessidade de maior destaque para as histórias do Largo (e da cidade), para além dos importantes, mas tímidos cartazes expostos em uma parte do sítio.

$\mathrm{O}$ rosário voltaria às oficinas na medida em que as religiões não hegemônicas na cidade se tornassem objeto das análises e debates. Foi o caso, em particular, da discussão dos "colares e pulseiras de contas" presentes no islamismo, no budismo, na umbanda e no candomblé, e com uma história milenar de associação a práticas de culto. ${ }^{40}$ Assim, ao rosário católico foi contraposto o misbaha islâmico, composto por 99 contas, utilizado na recitação dos 99 nomes de Allah; o japa mala budista tibetano, comporto por 108 contas, utilizado para a recitação de mantras relacionados aos "iluminados" de devoção pessoal; e finalmente, as guias do umbanda e do candomblé, associados à devoção aos orixás. ${ }^{41}$ Em cada um dos casos, as singularidades do uso e dos significados foram ressaltados, possibilitando comparações e exercitando conceitos das diferentes disciplinas que se debruçaram sobre o fenômeno religioso. Assim, por exemplo, as contas nas diferentes tradições religiosas foram interpretadas como objetos que possibilitavam a comunicação com o sagrado, diferindo nas formas pelas quais essa comunicação se realizava (pela recitação, articulando a fala e o movimento manual de contagem, e/ ou pelo uso do objeto como parte da vestimenta, no pescoço, no punho, no tornozelo ou dependurado pelos ombros) assim como nos benefícios trazidos por sua utilização (afastamento dos males, garantia de promessas, alteração de estados mentais, perfeição ritualística etc.). Nos estudos do meio realizados nos sítios religiosos dessas religiões (a Sociedade Islâmica de Campinas, o templo budista Higashi Honganji, a praça Rui Barbosa durante o $3^{\circ}$. Dia de Umbanda de Campinas), foi possível observar a utilização ou não desses, tornando possível a reflexão a respeito das polêmicas do modos de interação material entre sagrado e profano nas diferentes religiões.

\section{Considerações finais}

Procuramos defender que a reflexão sobre o culto ao Rosário em Campinas, em suas diferentes dimensões espaciais e temporais, é uma importante estratégia tanto para a promoção da tolerância religiosa como para a valorização do patrimônio cultural local, em particular no contexto da extensão universitária. Os processos de flutuação e apagamento da memória cívica, ao invés de negados, devem ser trabalhados

40 DUBIN, Louis Sherr. The History of Beads, from 30,000 B.C. to the present. New York: Abrams, 2009.

${ }^{41}$ Associados a personagens do cristianismo, como na umbanda, ou não, como no candomblé contemporâneo. Sobre o processo de "africanização" do candomblé, cf. PRANDI, Reginaldo. O Brasil com axé: candomblé e umbanda no mercado religioso. Estudos Avançados, v. 18, n. 52, p. 223-238, 2004. 
e discutidos criticamente como mecanismos para a compreensão de processos sociais mais amplos. O tratamento crítico das informações é uma das condições para a construção de relações democráticas entre os diferentes sujeitos sociais, e o patrimônio religioso campineiro, em sua diversidade, não pode ficar limitado à imagem nebulosa da memorialística ou à celebração elitista dos monumentos culturais ${ }^{42}$, mas deve, pelo contrário, ser incorporado de modo rigoroso e consistente nas práticas escolares como mecanismo de combate à intolerância e construção de relações democráticas entre os sujeitos e o espaço urbano.

\section{Referências}

ARNOLD, Dana; ERGUT, Elvan Altan; ÖZKAYA, Belgin Turan (eds). Rethinking Architectural Historiography. London; New York, 2006.

BADARÓ, Ricardo. Plano de Melhoramentos Urbanos de Campinas (1934-1962). 1986. Dissertação (Mestrado) - Faculdade de Arquitetura e Urbanismo, Universidade de São Paulo, São Paulo, 1986.

1996.

. Campinas, o despontar da modernidade. Campinas: Centro de Memória da Unicamp,

BELL, Catherine. Ritual. Perspectives and Dimensions. Oxford: Oxford University Press, 1997. BERGMANN, Sigurd (ed.). Architecture, Aesth/Ethics and Religion. Frankfurt am Main; London: IKO-Verlag für Interkulturelle Kommunikation, 2005

BOSS, Sarah Jane. Telling the Beads: the practice and symbolism of the rosary. In: BOSS, Sarah Jane. (ed). Mary: the complete resource. London: Continuum, 2007. p. 385-394.

BRUNEAU, Philipe. Quatre propos sur l'archéologie nouvelle. Bulletin de correspondance hellénique, v. 100, n. 1, p. 103-135, 1976.

CARPINTERO, Antônio Carlos Cabral. Momento De Ruptura: as transformações no centro de Campinas na década dos cinqüenta. Campinas: Centro de Memória da Unicamp, 1996.

CASTRO, Marina. Igreja Nossa Senhora do Rosário: a não preservação de um patrimônio urbano em 1956. 2014. Monografia (Especialização em História e Patrimônio Cultural) - Pontifícia Universidade Católica de Campinas, Campinas, 2014.

CONDEPACC [Conselho de Defesa do Patrimônio Artístico e Cultural de Campinas]. Tombamento da Praça Visconde de Indaiatuba. Campinas, 1994.

DINSMOOR Jr., William. Anchoring Two Floating Temples. Hesperia, v. 51, p. 410-452, 1982. DROOGAN, Julian. Religion, Material Culture and Archaeology. London: Bloomsbury, 2013. DUBIN, Louis Sherr. The History of Beads, from 30,000 B.C. to the present. New York: Abrams, 2009.

FOUCAULT, Michel. De espaços outros. Estudos Avançados, v. 27, n. 79, p. 113-122, 2013.

FREHSE, Fraya. Potencialidades do método regressivo-progressivo. Pensar a cidade, pensar a história. Tempo Social, v. 13, n. 2, p. 169-184, 2001.

GONÇALVES, C.; MARCONDES, M. A Coleção Fotográfica V-8. Anais do Museu Paulista, São Paulo, (nova série) v. 13, n. 1, p. 253-269, jan./jun. 2005.

GONÇALVES, Denise. Uma história da historiografia de arquitetura - texto e imagem na definição de uma disciplina. ArtCultura, Uberlândia, v. 12, n. 20, p. 95-115, jan./jun. 2010.

42 MENESES, Ulpiano Toledo Bezerra de. A cidade como bem cultural: áreas envoltórias e outros dilemas, equívocos e alcance da preservação do patrimônio ambiental urbano. In: MORI, V. et al. (org.). Patrimônio: atualizando o debate. São Paulo: $9^{\mathrm{a}}$ SR/IPHAN, 2006. p. 33-76. 
HABU, Junko; FAWCETT, Clare; MATSUNAGA, John. Evaluating Multiple Narratives: Beyond Nationalist, Colonialist, Imperialist Archaeologies. Springer: New York, 2008.

INSOLL, Timothy. Archaeology, Ritual, Religion. London; New York: Routledge, 2004.

KIDDY, Elizabeth. Congados, Calunga, Candombe: Our Lady of the Rosary in Minas Gerais, Brazil. Luso-Brazilian Review, v. 37, n. 1, p. 47-61, 2000.

KNOTT, Kim. Spatial theory and method for the study of religion. Temenos, v. 41, n. 2, p. $153-$ 184, 2005.

LAHON, Didier. Esclavage et Confréries Noires au Portugal durant l'Ancien Régime (14411830). 2001. Tese (Doutorado) - École des Hautes Études en Sciences Sociales, Paris, 2001.

LEFEBVRE, Henri. Problèmes de Sociologie Rurale: La Communauté Paysanne et ses Problémes Historico-Sociologiques. Cahiers Internationaux de Sociologie, v. 6, p. 78-100, 1949.

. Perspectives de la Sociologie Rurale. Cahiers Internationaux de Sociologie, v. 14, p. $\overline{122-140,1953 .}$

MENESES, Ulpiano Toledo Bezerra de. A cultura material no estudo das sociedades antigas. Revista de História, n. 115, p. 103-117, 1983.

. A cidade como bem cultural: áreas envoltórias e outros dilemas, equívocos e alcance da preservação do patrimônio ambiental urbano. In: MORI, V. et al. (org.). Patrimônio: atualizando o debate. São Paulo: $9^{\text {a }}$ SR/IPHAN, 2006. p. 33-76.

MITCHELL, Nathan. The Mystery of the Rosary: Marian Devotion and the Reinvention of Catholicism. New York: New York University Press, 2009.

OTTO, Christian. Program and programs. In: ARNOLD, D.; ERGUT, E.; ÖZKAYA, B. (eds). Rethinking Architectural Historiography. London; New York, 2006. p. 50-59.

PARETO JR., Lindener. Pândegos, rábulas, gamelas: os construtores não diplomados entre a engenharia e a arquitetura (1890-1960). 2016. Tese (Doutorado) - Faculdade de Arquitetura e Urbanismo, Universidade de São Paulo, 2016.

PARK, Chris. Religion and Geography. In: HINNELLS, J. (ed.). The Routledge Companion to the Study of Religion. London; New York: Routledge, 2005. p. 439-55.

PASSOS, João Décio; USARSKI, Frank (orgs.). Compêndio de Ciência da Religião. São Paulo: Paulinas; Paulus, 2013.

PRANDI, Reginaldo. O Brasil com axé: candomblé e umbanda no mercado religioso. Estudos Avançados, v. 18, n. 52, p. 223-238, 2004.

PREFEITURA MUNICIPAL DE CAMPINAS. Obras de revitalização da Francisco Glicério seguem em ritmo acelerado [Notícia publicada no dia 06/03/2015, às 19:15]. Portal da Prefeitura Municipal de Campinas. Disponível em: $<$ http://www.campinas.sp.gov.br/noticias-integra. php?id=26226>. Acesso em: dez. 2015.

QUINN, Philip; TALIAFERRO, Charles (eds.). Companion to Philosophy of Religion. Oxford: Blackwell, 1999.

REGINALDO, Lucilene. Os Rosários dos Angolas: irmandades de africanos e crioulos na Bahia setecentista. São Paulo: Alameda, 2011.

ROSADA, Mateus. Sob o signo da cruz: Igreja, Estado e secularização (Campinas e Limeira 1774-1939). 2010. Dissertação (Mestrado) - Escola de Engenharia de São Carlos, Universidade de São Paulo, São Carlos, 2010.

SARAMAGO, Ligia Teresa. A topologia do ser: lugar, espaço e linguagem no pensamento de Martin Heidegger. Rio de Janeiro: PUC-Rio; Loyola, 2008.

SCHIFFER, Michael. Behavioral Archaeology. New York: Academic Press, 1976.

SEGAL, Robert (ed.). The Blackwell Companion to the Study of Religion. Oxford: Blackwell, 2006. 
SILVA, Eliane Moura da. Entre religião, cultura e história: a escola italiana das religiões. Revista de Ciências Humanas, Viçosa, v. 11, n. 2, p. 225-234, 2011.

SIMÃO, Maristela. As irmandades de Nossa Senhora do Rosário e os africanos no Brasil do século XVIII. 2010. Dissertação (Mestrado em História da África) - Faculdade de Letras, Universidade de Lisboa, 2010.

SMITH, Neil. Gentrificação, a fronteira e a reestruturação do espaço urbano. GEOUSP: espaço e tempo, n. 21, p. 15-31, 2007.

SOUZA, Juliana Beatriz Almeida de. Viagens do Rosário entre a Velha Cristandade e o Além-Mar. Estudos Afro-Asiáticos, ano 23, n. 2, p. 1-17, 2001.

STANEK, Lukasz. Architecture as Space, Again? Notes on the 'Spatial Turn'. Spéciale 'Z, Paris, n. 4, p. 48-53, 2012.

STEGANHA, Roberta. Escavações revelam parte da antiga Igreja do Rosário em Campinas, SP. Portal G1 Campinas e Região, publicada em 30/06/2015, às 07h01. Disponível em: <http:// g1.globo.com/sp/campinas-regiao/noticia/2015/06/escavacoes-revelam-parte-da-antiga-igreja-do-rosario-em-campinas-sp.html>. Acesso em: 25 mar. 2016.

TINHORÃO, José Ramos. Os Negros em Portugal. Uma presença silenciosa. Lisboa: Caminho, 1997.

WARF, Barney; ARIAS, Santa (eds.). The Spatial Turn: Interdisciplinary Perspectives. Routledge: New York, 2009.

WESLER, Kit. An Archaeology of Religion. Lanham: University Press of America, 2012.

WIEBE, Paul. The Architecture of Religion: A Theoretical Essay. San Antonio: Trinity University Press, 1984.

WINSTON-ALLEN, Anne. Stories of the Rose: The Making of the Rosary in the Middle Ages. Philadelphia: Pennsylvania University Press, 1997.

WHYTE, William. How Do Buildings Mean? Some Issues of Interpretation in the History of Architecture. History and Theory, v. 45, n. 2, p. 153-177, 2006.

ZAKIA, Sílvia Amaral Palazzi. Construção, arquitetura e configuração urbana de Campinas nas décadas de 1930 e 1940: o papel de quatro engenheiros modernos. 2012. Tese (Doutorado)

- Faculdade de Arquitetura e Urbanismo, Universidade de São Paulo, São Paulo, 2012. 